\title{
O PORTO DE ARATU NO CONTEXTO INDUSTRIAL BAIANO: INDICADORES DE DESEMPENHO E OS OPERADORES PORTUÁRIOS
}

\author{
The Port of Aratu in the Industrial Context Baiano: \\ Pointers of Performance and the Port Operators
}

\author{
Ricardo Bahia Rios \\ Universidade do Estado da Bahia - Campus XI \\ Serrinha/ Bahia - Brasil \\ rbrios@uneb.br
}

Artigo recebido para publicação em 19/07/2009 e aceito para publicação em 05/11/2009

RESUMO: Os portos constituem-se em importantes equipamentos responsáveis pela interligação de boa parte da produção local com os mais diversos mercados. O porto de Aratu, atualmente responsável por mais de $60 \%$ da movimentação de carga no estado da Bahia, foi projetado estrategicamente para atender as crescentes necessidades de uma área industrializada, caracterizando-o como o primeiro e mais importante complexo portuário industrial do estado voltado para a movimentação de carga, basicamente de químicos, petroquímicos e metalúrgicos beneficiados na Região Metropolitana de Salvador (RMS). Características que o confere diferentes grau de importância na reprodução do capital, contribuindo para a inserção semiperiférica do estado da Bahia no sistema de circulação da economia brasileira e internacional.

Palavras-chave: Porto. Infraestrutura. Desenvolvimento Urbano-Regional.

ABSTRACT: The ports are important equipments points responsible for the interconnection of great part of the local production with the most diverse markets. On the other hand, the port of Aratu, currently responsible for more than $60 \%$ of the load movement in the state of the Bahia, was projected strategically to take care of the increasing necessities of an industrialized area, characterizing it as the first and the most important industrial port complex of that state involved mainly with chemistries, petrochemical and metallurgic benefited in the Metropolitan Region of Salvador (RMS). Characteristics that confer them a specific degree of importance in the reproduction of the capital, contributing for the semi peripheral insertion of Bahia state in the system of circulation of Brazilian and international economy.

Keywords: Port. Infrastructure. Urban-Regional development. 


\section{INTRODUÇÃO}

A necessidade de um porto industrial que atendesse exclusivamente a Região Metropolitana de Salvador (RMS) delineava-se ao passo que a economia baiana provia transformações, ora com maior vigor, ora não. Dessa forma, para entender a função estratégica que Aratu desempenha hoje é preciso sublinhar alguns aspectos marcantes da economia baiana entre os meados do século passado ao início do século XXI.

Durante um longo período, a base da economia soteropolitana e de sua tradicional região, o Recôncavo Baiano, persistia ligada à evolução das exportações de produtos primários (agrícolas e minerais). De maneira ampla, a pauta de exportação baiana incluía algumas dezenas de commodities, entre eles somente três itens se destacavam: cacau, açúcar e o fumo. Tal situação colocava a economia da Bahia numa posição de expansão limitada, à mercê das flutuações das crises cíclicas, típicas das economias agroexportadoras.

Entre os três itens de maior participação na economia, o mais eminente, sem dúvida, foi o cacau, que se constituiu no principal produto de exportação da Bahia até o final dos anos de 1960. A cacauicultura representou para o estado da Bahia a principal atividade econômica entre as décadas de 1910 e 1960. As dimensões básicas dessa cultura, entretanto, foram insuficientes para transformar a base do capital baiano agroexportador para o capital industrial, diferentemente das lavouras de café no Sudeste do país, o que acelerou o crescimento urbano-industrial do mesmo.

Assim, apesar da cacauicultura se destacar como o principal produto exportado pela Bahia, o mesmo não foi capaz de fornecer uma base de acumulação digna de criar as condições iniciais para o incremento da expansão industrial. Percebe-se que o modelo gerado pela cacauicultura era extremamente concentrado no beneficiamento do produto. A respeito Almeida (2006) argumenta que o:

Cacau permaneceu quase sempre restrito à secagem das amêndoas em condições rudimentares, o que gerou possibilidades de investimento agroindustrial limitadas, até mesmo inferiores às existentes nos casos do tabaco e da atividade canavieiro-açucareira.
Isso não excluiu o surgimento de um pequeno setor industrial de produção de derivados do cacau, concentrado em Salvador, setor que, no entanto, só conheceu alguma expansão a partir dos anos 40 (ALMEIDA, 2006, p. 13).

Além disso, é preciso destacar que uma parcela considerável do excedente criado pela cacauicultura acabou sendo deslocada para outras regiões do país, especialmente para o eixo Rio de Janeiro - São Paulo, atraída pelas melhores oportunidades de investimento em outras praças ou absorvida pelo comércio de outros centros.

Embora a cacauicultura tivesse fornecido subsídios financeiros importantes para o desenvolvimento da economia baiana, faltaram ampliações no investimento diversificado do capital, principalmente no setor industrial, capazes de ampliar a reduzida escala e o baixo dinamismo da economia até o final do século XX.

Historicamente, as redes econômicas e sociais que a capital (Salvador) drenou, não se constituíram em tese para o desenvolvimento diversificado da economia baiana. Entre os anos de 1920-1940, observase uma estagnação econômica em virtude de uma lenta implantação das relações capitalistas de produção, apoiada numa concentração fundiária e/ou de renda além de um incipiente desenvolvimento tecnológico industrial. Poucos centros urbanos na Bahia, até a metade do século XX, possuíam uma autonomia econômica e um desenvolvimento comercial significativo. Nesse período, até mesmo Salvador registrava um movimento comercial limitado, basicamente pelos fluxos de mercadoria que restringiam o dinamismo das cidades menores próximas do seu entorno, concentradas no Recôncavo e acessíveis por via marítima.

Contudo, a tenuidade das exportações limitava à expansão do mercado regional que, ao mesmo tempo, restringia o próprio crescimento do capital comercial em decorrência dos baixos níveis de investimentos tecnológicos. O que leva a concluir que as condições desfavoráveis marcaram a gênese da indústria baiana. Esse baixo desenvolvimento tecnológico industrial colaborou para que, até o início dos anos de 1950, não tivesse a necessidade de implantação de um porto que atendesse os interesses do capital industrial. Os portos de Salvador e Ilhéus encontravam-se bem en- 
caixados na lógica de acumulação da elite comercial baiana. Esse período de lento crescimento, marcado pelo débil dinamismo e/ou pelas sucessivas crises cíclicas das atividades agroexportadoras, muito dependente do consumo externo e dos condicionantes ambientais, são alguns dos fatores que justificavam a falta de investimento nos portos já existentes e na construção de um novo porto industrial para a região.

O contexto econômico da Bahia, e conseguinte o de Salvador, começou a transformar-se entre as décadas de 1950-1980 (TEIXEIRA; GUERRA, 2000). Esse período ilustra uma fase de requalificação dos espaços produtivos, apoiado numa industrialização convergente para o setor petroquímico e metalúrgico, período denominado por Almeida (2006, p. 20) como “a nova industria baiana”, que sobre as bases das "iniciativas estatais abriram caminhos para rápidas transformações”. Entre essas modificações destacam-se: 1) a construção da usina hidroelétrica de Paulo Afonso, que iria finalmente, resolver a questão da matriz energética para o desenvolvimento industrial; 2) a implantação das atividades de extração e refino do petróleo no Recôncavo; 3) a construção da rodovia Rio-Bahia (BR116); 4) a criação do Banco do Nordeste do Brasil (1954) e da Superintendência do Desenvolvimento do Nordeste (1959). Estas últimas contribuíram para a expansão da oferta de financiamentos públicos de baixo custo, amortizáveis em longo prazo, capazes de assegurar novos investimentos industriais e a modernização das unidades fabris já existentes, bem como no melhoramento de infraestrutura regional.

Todavia, o mais significativo acontecimento econômico do período foi proveniente da implantação da Petrobras, que resultou na construção do terminal marítimo de Madre de Deus e na implantação da Refinaria Landulpho Alves-Mataripe (RLAM). Este que cooperou para as transformações da economia baiana, centrada na expansão de novas indústrias no entorno de Salvador que visavam o aproveitamento das matérias-primas disponibilizadas pela RLAM.

Mesmo que timidamente, até o final da década de 1950, o Estado da Bahia tinha iniciado o seu processo de industrialização, principalmente a partir de impulsos exógenos e concentradores, abalizado num desenvolvimento típico cidade-industrial-linear, nos arredores da Bahia de Todos os Santos, possuindo a capital como centro do sistema (SAMPAIO, 1999).

Outro grande impulso na qualidade evolutiva da indústria baiana dar-se-ia a partir de 1967, em virtude dos investimentos nas fábricas do Centro Industrial de Aratu (CIA) e do Complexo Petroquímico de Camaçari (COPEC) implantadas entre 1972-1978, reflexos dos efeitos da política de desconcentração industrial. Além dos incentivos federais, o Governo Estadual passou a ofertar uma infraestrutura para a implementação das indústrias em uma área concentrada próxima à capital, composta de facilidades portuárias, rodovias, ferrovias etc.

Nesse período, Teixeira; Guerra (2000) explicam que:

O número de projetos atraídos para o CIA $e$ demais distritos industriais baianos foi impressionante. Em dezembro de 1969, havia 100 projetos aprovados pela Sudene, dos quais 37 em funcionamento, 43 em análise e 33 com carta de opção para virem a se instalar. Todos esses investimentos criariam um total de mais de 30 mil empregos diretos. Ao contrário do que recomendava o GTDN, porém, $85 \%$ dos investimentos destinavam-se ao setor de bens intermediários, revelando, desde então, a vocação industrial do estado. É dessa época, a implantação da Usiba, Sibra e Ferbasa, por exemplo. Vale notar, ainda, que o CIA $e$ seu entorno passam a sediar novas empresas químicas, a exemplo da CQR, Paskin, Tibrás, Ciquine, Fisiba e, posteriormente, a Dow, antes mesmo da implantação do Pólo Petroquímico de Camaçari (TEIXEIRA; GUERRA, 2000, p. 86).

Operando em grande escala e com tecnologia de ponta, essas novas unidades fabris, implantadas entre 1970 e 1980, e outras balizadas na siderurgia (SIBRA, FEBRASA e USIBA) e na mineração-metalurgia do cobre (Caraíba Metais em 1984) alteraram completamente o perfil da economia baiana, conseqüentemente, causando intenso impacto na capital e na sua região de influência imediata. Em resumo, como afirmou Almeida (2006, p. 25) que "[...] de um ponto muito restrito, levando-se em conta apenas o produto e a 
estrutura setorial da sua economia, poder-se-ia dizer que a economia baiana, e principalmente a de Salvador e sua periferia, havia se industrializado".

Consolidado o processo de industrialização que inseriu a Bahia na matriz periférica industrial brasileira, por meio da chamada "especialização regional", direcionada para o setor petroquímico e metalúrgico, a participação relativa do setor primário no PIB setorial baiano diminuiu de 40\% em 1960, para 16,4\% em 1980. O setor secundário, por sua vez, no mesmo período, quase triplica sua participação, que salta de $12 \%$ para 31,6\% (TEIXEIRA; GUERRA, 2000).

Essas indústrias, por se caracterizarem em unidades produtoras de bens intermediários voltadas para o mercado externo, tornaram a economia regional fortemente vinculada à nacional e internacional. Verificase que a penetração dos petroquímicos baianos no mercado nacional e internacional contribuiu para o aumento das exportações. Estava, então, estabelecido o cenário para a construção de um porto altamente especializado que atendesse as novas demandas das indústrias recém instaladas no entorno de Salvador.

O projeto de construção de um porto localizado na Baía do Caboto no município de Candeias inicia-se atrelado ao projeto de implantação do CIA, na década de 1970. O projeto partia do pressuposto que o pólo industrial reconfiguraria o perfil econômico do Estado, necessitando, portanto, de suporte portuário para o escoamento de suas produções sucumbindo na necessidade da instalação de um porto com características específicas que atendessem a demanda de uma região recém industrializada. Desta forma, em 1971, tiveram início as obras de instalação do porto por intermédio de parceria da iniciativa privada com o Governo da Bahia, porém somente a partir da constituição da Companhia Docas da Bahia (CODEBA) em 1977 (onde instalações de Aratu foram incorporadas ao patrimônio da Companhia), o Governo baiano passou a compor seu quadro de acionistas.

O porto industrial de Aratu foi idealizado para constituir uma plataforma logística que atendesse as novas demandas ocasionadas pela "nova indústria” instalava na RMS. Dessa forma, o porto contribuiu de certa forma para o fortalecimento da indústria baiana, possibilitando a circulação das riquezas produzidas pelas fábricas.
Atendendo a produção industrial da RMS, a quinta região metropolitana do país e a primeira do Nordeste em termos de valor, com um PIB de aproximadamente de R\$ 31 bilhões (ALMEIDA, 2006), o porto de Aratu atualmente concentra $60 \%$ do volume de operações da CODEBA, oferecendo suporte indispensável ao CIA, conforme previsto no projeto inicial, como, também, ao Pólo Petroquímico de Camaçari e ao desenvolvimento da atividade metalúrgica no Estado (CODEBA, 2006).

Sem dúvida, o desenvolvimento das atividades de exploração e refino de petróleo no Recôncavo Baiano nos anos de 1950, com destaque para a entrada em operação da Refinaria Landulfo Alves-Mataripe (RLAM). Logo em seguida, os impactos gerados pelo incentivo fiscal, que resultou na implantação do CIA, tornou a industrialização baiana mais incisiva em decorrência das atividades petroquímicas e metalúrgicas, embora identificado o baixo dinamismo industrial, principalmente as registradas nos anos de 1990. Estas foram recentemente superadas pelas novas possibilidades provocadas pela "guerra fiscal" que atraiu para a Bahia, e mais especificamente para a RMS, novas indústrias especialmente as ligadas ao setor automobilístico (ALMEIDA, 2006; SILVA; SILVA, 2003; TEIXEIRA; GUERRA, 2000; UDERMAN, 2000).

Para análise e compreensão da problemática em questão, a pesquisa desenvolveu-se de forma associada, aplicando uma metodologia que envolve procedimentos de pesquisa de campo e bibliográfica, utilizando técnicas estatísticas, obtendo, assim, uma visualização holística das conectividades portuárias existentes. No primeiro momento, fez-se necessário um levantamento de estudos já existentes sobre a temática para uma reflexão mais ampla do objeto em estudo. Posteriormente, para o entendimento da funcionalidade da atividade portuária, foram realizadas visitas técnicas e entrevistas com os coordenadores de gestão portuária do porto de Aratu, objetivando o conhecimento do funcionamento e da estrutura portuária existente. Após as entrevistas, foram realizadas vistas ao Centro de Documentação e Informação da CODEBA, onde tivemos acesso aos relatórios estatísticos anuais dos anos de 1996 a 2006, referentes às atividades de embarque e desembarque realizadas pelo porto. Tal recorte temporal foi escolhido por represen- 
tar uma fase de reestruturação das atividades portuárias, corresponde exatamente ao período intermediário pré e pós-reforma portuária, que nos possibilitou o entendimento das implicações da Lei de Modernização dos Portos (LMP) nas operações e gestões portuárias.

Preteritamente ou atualmente, a necessidade de um porto tipicamente graneleiro, constituído de terminais especializados na movimentação de granéis sólidos, líquidos e produtos gasosos, capazes de atender a circulação de uma produção regional, representa um fator importante para a promoção do movimento contínuo dos fluxos de capital de qualquer região. De maneira generalizada, avalia-se que a disponibilidade de uma região detentora de matéria-prima e capacitada de uma infraestrutura de transporte e comunicação eficientes constituíram fatores significativos, porém, não decisivos, para o desenvolvimento de uma base industrial econômica integrada ao mercado externo, representando um fator substancial para a elevação da economia baiana.

\section{OS INDICADORES DE DESEMPENHO E OS OPERADORES PORTUÁRIOS}

Os indicadores das atividades portuárias desenvolvidas em Aratu constatam o desempenho favorável, principalmente pós-reforma da legislação específica do setor. De modo geral, o porto registrou bons resultados, comparados como os demais portos baianos e nacionais. Um bom sinal desse desempenho constitui-se na pesquisa proferida pelo Centro de Estudos em Logística (CEL) em 2008, no qual o porto de Aratu galgou uma boa avaliação entre os 18 principais portos em movimentação do Brasil. No entendimento dos principais usuários, o porto de Aratu atingiu a média 7,1, dessa forma, classificado com uma "Bom porto" (GRÁF. 1).

Obtendo uma boa avaliação, Aratu ficou na frente de importantes atracadouros como o de São Francisco do Sul, Itajaí, Paranaguá etc.

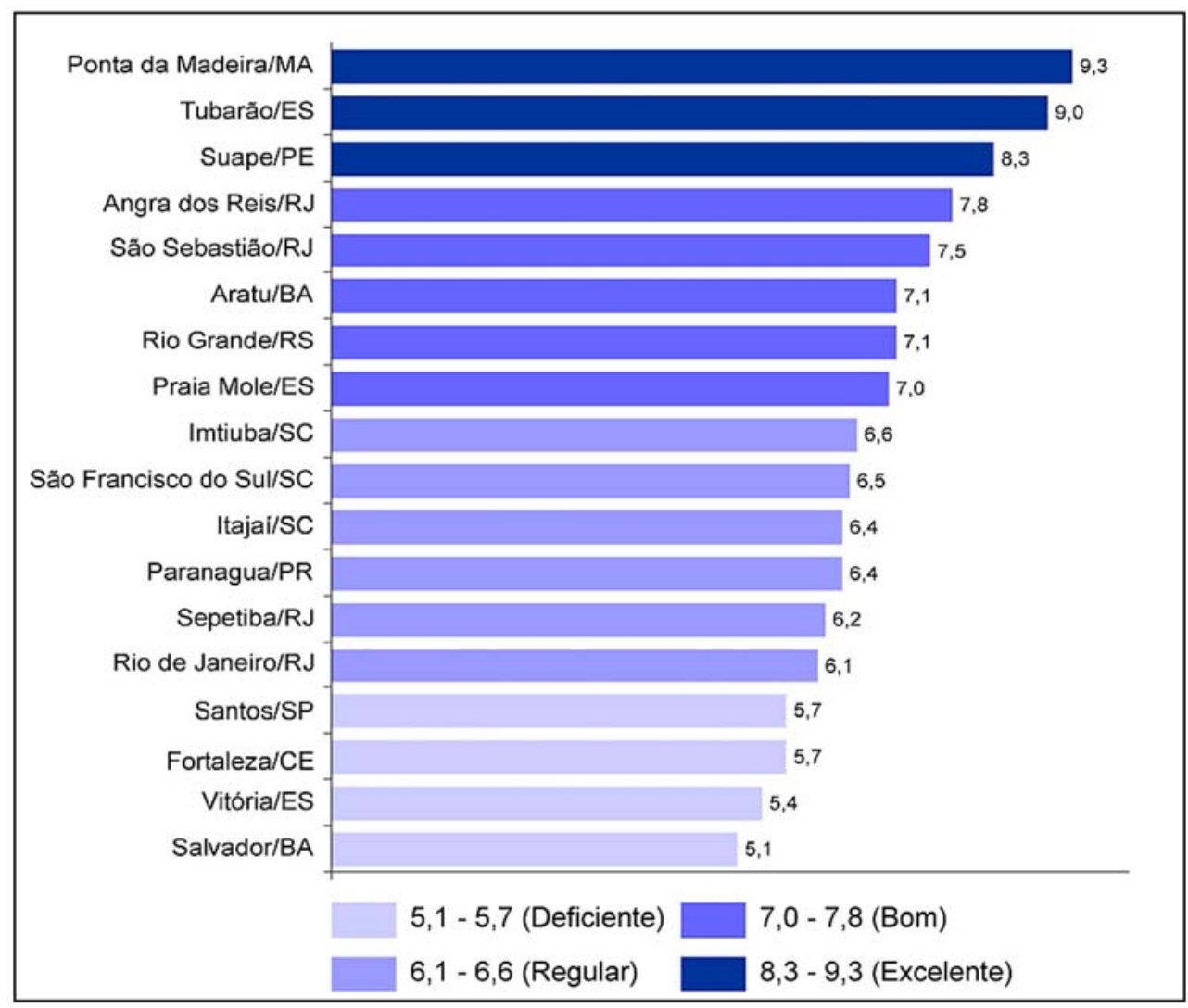

GRÁFICO 1: Avaliação dos Portos Brasileiros Fonte: CEL, 2008. 
Na percepção dos principais usuários o porto atende, mesmo que parcialmente, alguns requisitos básicos que lhe afere uma boa performance. Contudo, a Associação dos Usuários dos Portos da Bahia (USURPORT), identificou, durante o III Seminário Nacional de Modernização dos Portos (realizado em
Salvador no mês de março de 2008), que mesmo perante satisfatória avaliação a infraestrutura do porto encontra-se bem defasada em conseqüência dos baixos investimentos para o melhoramento das instalações. O QUADRO 1 sintetiza as principais causas, suas conseqüências e possíveis melhorias.

\begin{tabular}{|c|c|c|c|}
\hline Principais causas & Causas geradoras & Conseqüências & Melhorias \\
\hline $\begin{array}{l}\text { Equipamentos } \\
\text { deteriorados e antigos } \\
\text { (balança com quebras } \\
\text { freqüentes impedindo } \\
\text { saída de carga) }\end{array}$ & $\begin{array}{l}\text { Falta de manutenção } \\
\text { e de capacidade de } \\
\text { investimento em } \\
\text { novos equipamentos. }\end{array}$ & $\begin{array}{l}\text { Baixo ritmo nas } \\
\text { operações do TGS Sul: } \\
\text { média de } 3.889 \text { tons/dia } \\
\text { e elevado número de } \\
\text { quebra } \\
\text { equipamentos. }\end{array}$ & $\begin{array}{l}\text { Foco em manutenção } \\
\text { preventiva. }\end{array}$ \\
\hline $\begin{array}{l}\text { Baixo ritmo } r \text { de } \\
\text { descarga no granel } \\
\text { sólido (TGS Sul } 3.889 \\
\text { tons/dia). }\end{array}$ & $\begin{array}{l}\text { Equipamentos } \\
\text { operando muito } \\
\text { abaixo da sua } \\
\text { capacidade nominal, } \\
\text { além de constantes } \\
\text { quebras. }\end{array}$ & $\begin{array}{l}\text { Navios ocupando o } \\
\text { berço por mais tempo, } \\
\text { elevando os custos de } \\
\text { espera (demurrage). }\end{array}$ & $\begin{array}{l}\text { Manutenção e novos } \\
\text { equipamentos para o } \\
\text { aumento dos ritmos } \\
\text { operacionais. }\end{array}$ \\
\hline $\begin{array}{l}\text { Baixa produtividade } \\
\text { do TGS Sul. }\end{array}$ & $\begin{array}{l}\text { Portifólio variado de } \\
\text { produtos } \\
\text { descarregados. }\end{array}$ & $\begin{array}{l}\text { Não utilização da } \\
\text { capacidade nominal do } \\
\text { equipamento. }\end{array}$ & $\begin{array}{l}\text { Berço especializado } \\
\text { baseado em ritmos } \\
\text { mínimos de descarga. }\end{array}$ \\
\hline $\begin{array}{l}\text { Calado não compatível } \\
\text { ao fluxo de navios. }\end{array}$ & $\begin{array}{l}\text { Falta de investimento } \\
\text { em dragagem. }\end{array}$ & $\begin{array}{l}\text { Porto fica fora das rotas } \\
\text { de grandes navios, } \\
\text { ocasionando redução da } \\
\text { oferta de navios. }\end{array}$ & $\begin{array}{l}\text { Realizar dragagem para } \\
\text { que o calado seja } \\
\text { superior a } 12 \text { metros. }\end{array}$ \\
\hline $\begin{array}{l}\text { Falta de espaço para } \\
\text { armazenagem. }\end{array}$ & $\begin{array}{l}\text { Estagnação de oferta } \\
\text { e implementação de } \\
\text { novos projetos. }\end{array}$ & $\begin{array}{l}\text { Baixa produtividade e } \\
\text { custos adicionais. }\end{array}$ & $\begin{array}{l}\text { Licitação de novas } \\
\text { áreas pela CODEBA. }\end{array}$ \\
\hline
\end{tabular}

QUADRO 1: Principais problemas identificados no porot de Aratu Fonte: USUPORT, 2008.

Dentre as benfeitorias esperadas para Aratu, destaca-se a requalificação dos equipamentos existentes de modo a atingir, pelo menos, 50\% de suas respectivas capacidades nominais; dragagem para 15 metros; ampliação das áreas de estocagem por meio de arrendamentos e até mesmo investimento privado em píer de atracação.
O acesso rodoviário é facilitado pela rápida conexão com a rodovia BR-324 que se interliga com a BR-110 e BR-116, facilitando o escoamento da produção. Por intermédio de ramal com $10 \mathrm{~km}$ de extensão de ferrovias, o porto mantém conexão com a malha Centro-Leste da Ferrovia Centro Atlântica S.A. Embora observe a utilização do modal ferroviário, o 
nível de serviços oferecidos pelo modal ainda não é plenamente adequado (BAHIA, 2004). Significativa parcela da produção de petroquímicos transportada para a região Sudeste apóia-se no uso intensivo do modal rodoviário via BR-116 (BAHIA, 2004).
Contudo, entre os portos avaliados pela CEL, 33\% dos usuários apontaram o acesso rodoviário como deficiente (GRÁF. 2), em virtude das péssimas condições das estradas Baianas. Colocando o porto metropolitano entre os de melhor acesso rodoviário do país.

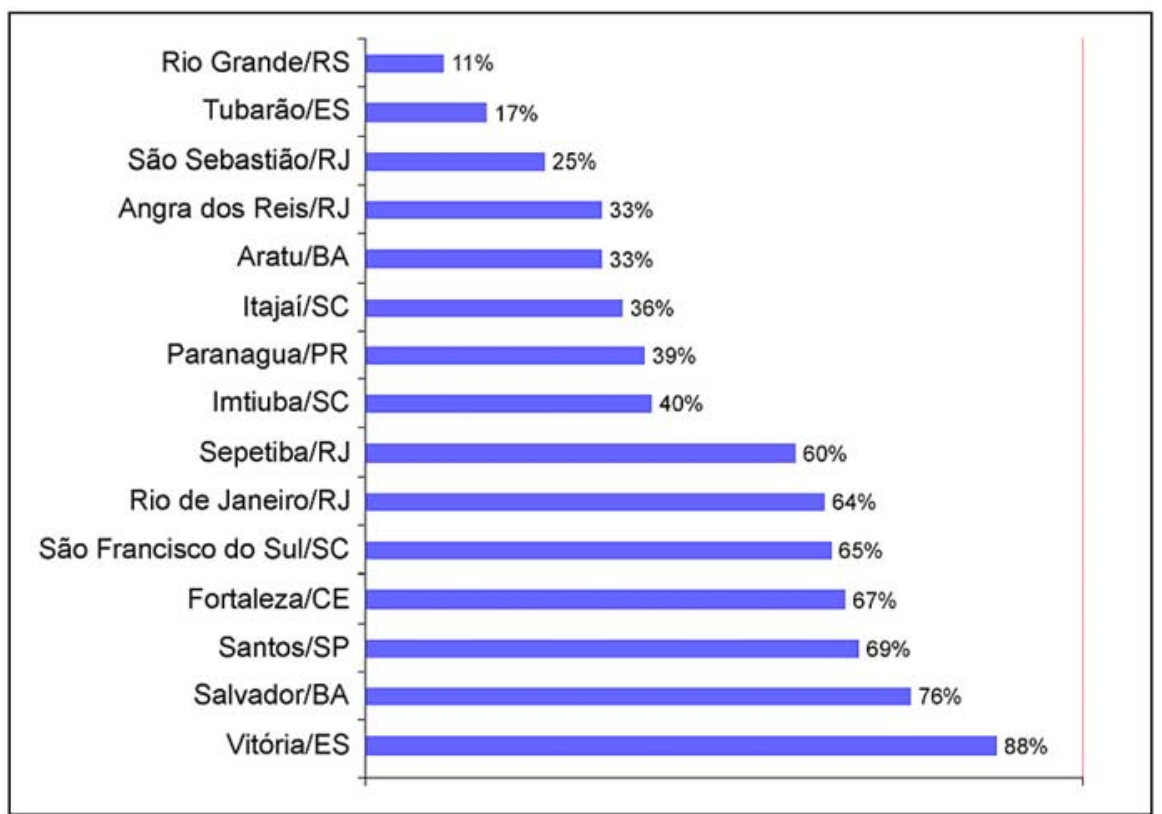

GRÁFICO 2: Problema com o acesso Rodoviário nos Portos/ Pesquisa com Embarcadores Fonte: CEL, 2008.

Outro indicador que registrou bom índice, corresponde ao tempo de espera para atracação, em média de 47,1 horas de espera dentro da média nacional para movimentação de granel sólido, GRÁF. 3.

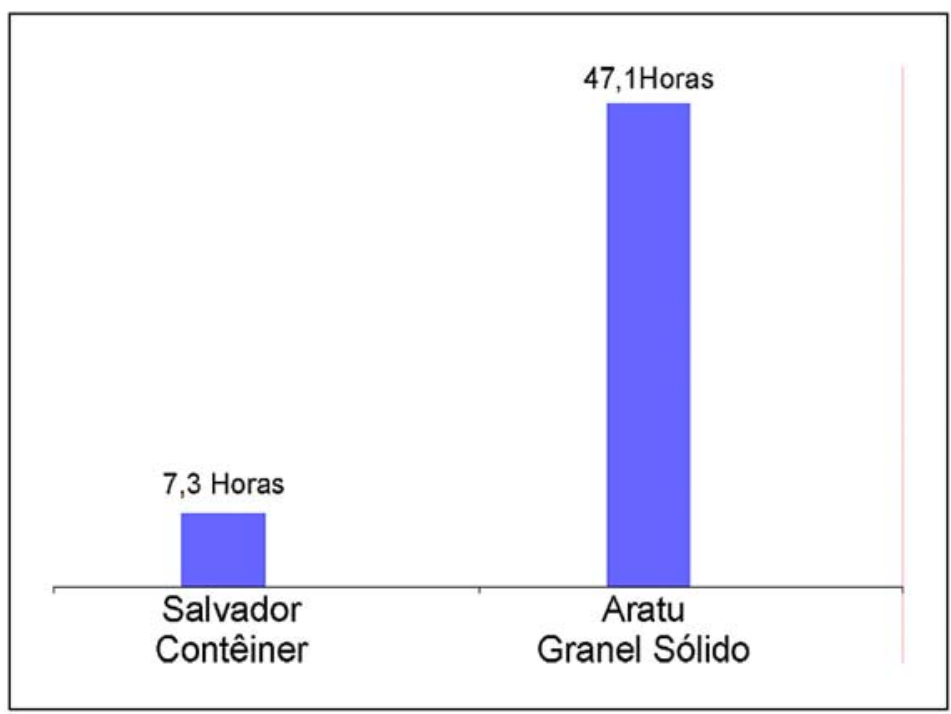

GRÁFICO 3: Tempo médio de espera para atracação do navio segundo Armadores e Agentes Fonte: CEL, 2008. 
Quanto ao quesito analisado referente a receita cambial, observa-se que o porto ao longo do período de 2000 - 2006, teve um comportamento favorável para o crescimento, tanto para as exportações quanto para as importações. Independente do aumento do volume de carga movimentada a partir dos anos de 2004 a receita cambial vem seguindo um ritmo de crescimento satisfatório (GRÁF. 4). Tais incrementos (receita e volume) tornam mais plausíveis os bons indicadores de desempenho registrados, embora, nos anos de 2005 e 2006 tenha ocorrido uma redução no montante total de carga o mesmo não interferiu no aumento das receitas. Esse comportamento pode ser associado à valorização internacional e à boa aceitação dos commodities movimentados via Aratu. Em certo, o porto só não registrou melhores índices em virtude da desvalorização cambial do dólar, o que vem sendo motivo de grandes reclamações por parte dos exportadores brasileiros (CODEBA, 2007).

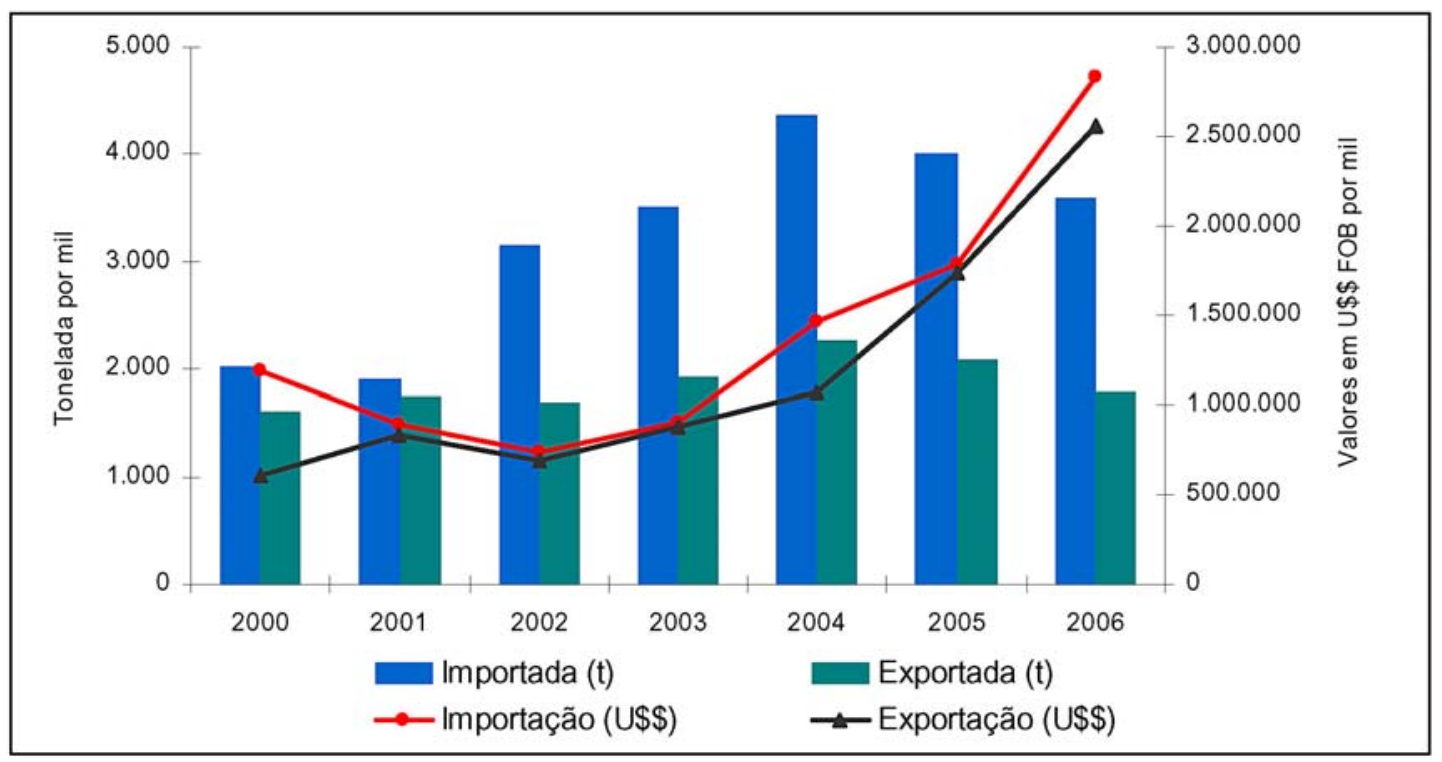

GRÁFICO 4: Porto de Aratu: valores de importação e exportação e tonelada movimentada - 2000-2006 Fonte: CODEBA, 2007.

A participação do porto na Balança Comercial é bastante significativa. Segundo os dados do Ministério do Desenvolvimento, Indústria e Comércio Exteri- or, no ano de 2006, o porto de Aratu foi o responsável por $63,1 \%$ de tudo que foi importado pelo Estado e 37,9\% das exportações Baianas, tiveram como ponto

TABELA 1: Porto de Aratu: tonelada movimentada por operador portuário qualificado - 2006

\begin{tabular}{lccc}
\hline Operador & Tonelada & Participação (\%) & Tipo de carga \\
\hline CABOTO & 1.141 .890 & 21,18 & G. Sólido \\
FAFEN & 4.2134 & 0,78 & G. Liquido/Gasoso \\
INTERNACIONAL & 6.7693 & 1,26 & G. Sólido \\
INTERMARÍTIMA & 35.9576 & 6,67 & G. Sólido \\
TEQUIMAR & 3.420 .963 & 63,44 & G. Líquido/Gasoso \\
VOPAK & 3.59 .830 & 6,67 & G. Líquido /Gasoso \\
Total & 5.392 .086 & 100 & \\
\hline
\end{tabular}

Fonte: CODEBA, 2007. 
de partida e chegada o porto de Aratu. De certo modo, isto revela um caráter concentrado das atividades de importação.

Atualmente, toda essa movimentação ocorre via seis operadores portuários (concentram 100\% das movimentações), TAB. 1, a TEQUIMAR constitui-se no principal, operando numa taxa de $63,44 \%$.

Segundo o presidente da CODEBA, espera-se um crescimento na movimentação em 2008, em razão da manutenção dos níveis de importação de cargas regulares, e incremento nas importações de fertilizantes e coque, bem como nas exportações de minério. Muito otimista como os indicadores, o mesmo, considera a possibilidade que nos próximos 5 anos a movimentação supere a casa dos 3.500 .000 toneladas. Porém para que essa previsão se torne realidade é preciso atrair novos investimentos para que haja aumento de produtividade.

A Braskem, uma das principais empresas usuárias do porto, aponta a necessidade de profundas melhorias na infraestrutura. Objetivando uma maior produtividade faz-se necessário, urgentemente, investimentos no aumento de pranchas na carga e descarga (terminais/navios), para que efetivamente o porto opere no sistema 24 horas. Além desses aspectos, é importante eliminar a restrição noturna (sinalização/iluminação), manutenção e aumento de calado (dragagem), tempos de operação/liberação, formação de lote (embarcadores), Inspetorias, Praticagem, Rebocadores, Polícia Federal, Receita Federal, Vigilância Sanitária, Capitania dos Portos e Investimento em novo berço de atracação.

\section{CONCLUSÃO}

Implantado estrategicamente para atender a demanda das indústrias localizadas na RMS, Aratu encontra-se longe de possuir instalações ideais, frente às reais e crescentes necessidades de circulação, aqui entendida como um circuito de produção composto pela produção-circulação-distribuição-consumo.

Dessa forma podemos aferir que à medida que a produção prescinde da circulação, a falta de investimentos na infraestrutura portuária em Aratu constituise num verdadeiro entrave para o desenvolvimento da região, visto que a circulação não é, no atual período, apenas circulação per se, ela é um conjunto de fatores tecnológicos, mas principalmente organizacionais que definem e organizam uma morfologia em que os lugares respondem a uma nova divisão do trabalho operacionalizada pelas redes (SILVA JUNIOR, 2007, p. 129).

Portando, como observado, mesmo como um cenário favorável, Aratu carece de melhorias na sua infraestrutura, de tal modo a favorecer o desenvolvimento das atividades indústrias que se encontram interligadas ao porto.

Em Aratu, observa-se um ambiente portuário voltado e/ou montado para atender os interesses hegemônicos de uma elite comercial e mais recentemente industrial, que por vez acabam caracterizando esses espaços como mero ponto de reprodução do capital, voltados exclusivamente para as questões de desenvolvimento econômico. Levando a concluir que o ser humano encontra-se pouco presente nas relações sociais do porto analisado.

Todavia, repensar o porto de Aratu no contexto metropolitano significa planejar e organizar um conjunto de ações, debate amplo com a participação efetivamente popular, sobre questões gerenciais, sociais, culturais etc, de modo que o porto deixe de ser exclusivamente compreendido como instâncias da reprodução economia, em prol dos grandes grupos que se apropriam desse importante espaço. Cabe também pensar o porto como instância social, mais participativo a vida da RMS e dos seus habitantes.

\section{REFERÊNCIAS}

ALMEIDA, Paulo Henrique de. A economia de Salvador e a formação de sua Região Metropolitana. In: CARVALHO, I.M.M; PEREIRA, G.C.(Coord). Como anda Salvador. Salvador: EDUFBA, 2006.

BAHIA. Secretaria de Infraestrutura. Programa Estadual de Logística de Transporte (PELTBAHIA): caminhos para o desenvolvimento. Salvador: SEINFRA, 2004. 
CENTRO DE ESTUDOS EM LOGÍSTICA (CEL). Análise e avaliação dos portos brasileiros 2008. Rio de Janeiro: COPPEAD/UFRJ, 2008. Disponível em: $<$ http://www.centrodelogistica.org $>$. Acesso em: 10 mar. 2008.

CODEBA. Porto de Salvador. Salvador, 2007. Disponível em: <http://www.CODEBA.gov.br/historico>. Acesso em: 15 jan. 2007.

SAMPAIO, A.H.L. Formas urbanas: cidade real e cidade-real; contribuição ao estudo urbanístico de Salvador. Salvador: Quarteto Editora, Faculdade de Arquitetura da UFBA, 1999.

SILVA JUNIOR, R.F. Geografia de redes e da logística no transporte rodoviário de cargas: fluxos e mobilidade geografia do capital. 270f. Dissertação (Mestrado em Geografia) - Faculdade de Ciências e Tecnologia, Universidade Estadual Paulista, 2004.

SILVA, S.C.B. de M. e; SILVA, B.C. Nentiwg. Estudos sobre globalização, territórios e Bahia. Salvador: Centro editorial e didático da UFBA, 2003.

TEIXEIRA, F. e GUERRA O. 50 Anos da Industrialização Baiana: do enigma a uma dinâmica exógena e espasmódica. Bahia Análise \& Dados, Salvador, v.10 n.1, Julho 2000, p.87-98.

UDERMAN, Simone. Perspectivas industriais. Tendências da Economia Baiana. Salvador: Seplantec, 2000.

ASSOCIAÇÃO DE USUÁRIOS DE PORTOS DA BAHIA(USUPORT). Notícias. Disponível em: $<$ http:/ /www.usuport.org.br/noticias.php?id=781>. Acesso em: 03 de mai. 2008. 